\title{
Assessment of Investment in Small Hydropower Plants
}

\author{
Perica Ilak ${ }^{1} \&$ Slavko Krajcar ${ }^{1}$ \\ ${ }^{1}$ Faculty of Electrical Engineering and Computing, University of Zagreb, Croatia \\ Correspondence: Perica Ilak, Faculty of Electrical Engineering and Computing, University of Zagreb, Zagreb, \\ HR-10000, Unska 3, Croatia. Tel: 385-1-6129-693. E-mail: perica.ilak@fer.hr
}

Received: May 15, 2013 Accepted: June 18, 2013 Online Published: July 26, 2013

doi:10.5539/eer.v3n2p33 URL: http://dx.doi.org/10.5539/eer.v3n2p33

\begin{abstract}
In this study an assessment of investments in a hydropower plants is considered. The objective of this work is to maximize the net present value from selling energy. Because of the stochastic nature of river flows, flow duration curve is constructed to take into account hydropower plant capacity factor, important for the assessment of investment. Proposed mixed-integer linear programming model is flexible and accounts for nonlinear three-dimensional (3-D) relationship between the produced power, the discharged water, and the head of the associated reservoir. Continuous chain of imaginary run-of-river plants is considered on the Sava river stretch (Croatia) from border with Slovenia to city of Sisak.
\end{abstract}

Keywords: assessment of investment, optimization, mathematical model, small hydropower plant, run-of-the-river, mixed-integer linear programming, Sava river, City of Zagreb

\section{Nomenclature}

$B$

$c\left(P_{\max }(i)\right)$

$d_{k}(i, t)$

$E 0_{l}(i)$

$E_{e}(i, t)$

$H_{\max }(i)$

$H_{r}(i)$

$H(i, t)$

$H$

I

$I_{>10 M W}$

$I_{\leq 10 M W}$

$i_{x}$

$I(t)$

$J$

$n$

$N_{I \times B}$

$N P V_{A \times B \times C}$

om $\left(P_{\max }(i)\right)$

on $(i, t)$
Set of indices of the blocks of the piecewise linearization of the unit performance curve $\mathrm{B}=\{1,2\}$, blok $\in B$.

Specific investment cost function $[€ / \mathrm{kW}]$.

$0 / 1$ variable used for discretisation of performance curves $k \in\{1,2\}$.

Minimal possible energy output of plant $i$ for performance curve $l, \quad l \in\{1,2\}$, [MWh].

Electricity produced for energy market by plant $i$ in time period $t[\mathrm{MWh}]$.

Maximal possible head of a pondage $i[\mathrm{~m}]$.

Rated head of a plant $i[\mathrm{~m}]$.

Head of pondage $i$ in time period $t[\mathrm{~m}]$.

Conversion factor equal to $3600\left[\mathrm{~m}^{3} \mathrm{~s} / \mathrm{m}^{3} \mathrm{~h}\right]$.

Set of indices of the reservoirs/plants, $I=\{$ 'Podsused ','Prečko','Zagreb1','Zagreb2', 'Zagreb3',Zagreb4'\}, $i \in I$.

Subset of plants with capacity above $10 \mathrm{MW}, I_{>10 M W} \subset I$.

Subset of plants with capacity of $10 \mathrm{MW}$ and under, $I_{\leq 10 \mathrm{MW}} \subset I$.

Inflation index.

Investment cost of a cascade in time period $t[€]$.

Set of indices of the perf. curves $J=\{1$-high lvl., 2-middle lvl., 3-low lvl. $\}, j \in J$.

Capacity factor.

Number of units scenario matrix of dimension $I x B$.

Depository matrix of $Q_{*, a}, Q_{*, b}, N_{*, c}$ combinations net present values of dimension $A x B x C$.

Specific operating and maintenance cost function [\%].

$0 / 1$ variable which is equal to 1 if plant $i$ is on-line in time step $t$. 
$O \& M(t) \quad$ Operating and maintenance cost of a cascade in time period $t[€]$.

$P_{\max }(i) \quad$ Capacity of plant $i[\mathrm{MW}]$.

$Q_{\min }(i) \quad$ Minimum water discharge of plant $i\left[\mathrm{~m}^{3} / \mathrm{s}\right]$.

$Q_{\max }(i) \quad$ Maximum water discharge of plant $i\left[\mathrm{~m}^{3} / \mathrm{s}\right]$.

$Q_{\text {res }}(i)$

Residual flow of plant $i\left[\mathrm{~m}^{3} / \mathrm{s}\right]$.

$Q_{I \times A}$

Rated flow scenario matrix of dimensions $I x A$.

$Q_{I \times A}$

Rated head scenario matrix of dimension $I x C$.

$q_{v}(i, t, b l o k)$

Variable water discharge of a plant $i$ in time period $t$ of block blok $\left[\mathrm{m}^{3} / \mathrm{s}\right]$.

$q(i, t)$

Total water discharge of plant $i$ in time step $t\left[\mathrm{~m}^{3} / \mathrm{s}\right]$.

$R(t)$

Revenue of a cascade in time period $t[€]$.

$r$

Discount rate.

$s(i, t)$

Spillage of the reservoir $i$ in time step $t\left[\mathrm{~m}^{3}\right]$.

T

Set of indices of the steps of the optimization period, $T=\left\{1,2, \ldots, T_{\max }\right\}, t \in T, T_{\max }$ $\in\{20,25,30\}$.

$U_{i} \quad$ Set of upstream reservoirs of plant $i$.

$V_{\text {min }}(i)$

$V_{\max }(i)$

Minimal possible utilizable volume of a plant $i\left[\mathrm{~m}^{3}\right]$.

$V(i, t)$

Maximal possible utilizable volume of a plant $i\left[\mathrm{~m}^{3}\right]$.

$W(i, t)$

Utilizable volume of a plant $i$ in time interval $t\left[\mathrm{~m}^{3}\right]$.

$w(i, t, b l o k)$

Forecasted natural water inflow of the reservoir $i$ in time step $t\left[\mathrm{~m}^{3}\right]$.

$0 / 1$ variable which is equal to 1 if water discharged by plant $i$ has exceeded block blok in time step $t$.

weight $(t) \quad$ Distribution of investment cost along $y$ time intervals, $t \in y \subset T$.

$X(i, t)$

Water content of the reservoir $i$ in time step $t\left[\mathrm{~m}^{3}\right]$.

$X_{\text {avg }}(i, t)$

Average water content of the reservoir $i$ in time step $t\left[\mathrm{~m}^{3}\right]$.

$X_{\max }(i)$

Maximal content of the reservoir $i\left[\mathrm{~m}^{3}\right]$.

$X_{l}(i)$

$l$-th discrete level of the content of the reservoir $i, l \in\{1,2\}\left[\mathrm{m}^{3}\right]$.

$X_{\min }(i)$

Minimal content of the reservoir $i\left[\mathrm{~m}^{3}\right]$.

$X(i, 0)$

Initial water content of the reservoir $i\left[\mathrm{~m}^{3}\right]$.

$X\left(i, T_{\max }\right)$

Final water content of the reservoir $i\left[\mathrm{~m}^{3}\right]$.

$Y$

Number of hours in one year, 8760 [h].

$\pi_{\text {fid }}(t)$

Feed-in-tariff in time step $t$ [€/MWh].

$\pi_{e}(t)$

Forecasted price of electricity in time step $t$ [€/MWh].

$\rho_{j}(i)$

Slope of the performance curve $j$ of plant $i\left[\mathrm{MWh} / \mathrm{m}^{3}\right]$.

$\rho_{v}$ (blok) Slope of the block blok of the utilizable volume function $\left[\mathrm{m}^{3} / \mathrm{m}^{3} / \mathrm{s}\right]$.

$\Delta Q_{\text {blok }}(i) \quad$ Maximum water discharge of block blok of plant $i \mathrm{~B}=\{1,2\}$, blok $\in B\left[\mathrm{~m}^{3} / \mathrm{s}\right]$.

\section{Introduction}

Harnessing a stream for hydroelectric power is a major undertaking and careful planning is a necessary if a profitable hydropower plant (HPP) is to result. At the same time country water laws and environmental concerns must be accounted (WVU, 1978) for detailed insight of environmental impacts of small HPP and how to they compare to other renewables is given in (Kucukali \& Baris, 2009). The general procedure in hydrologic study is to establish how much water is available to divert through turbine and the hydraulic head associated with this flow. 


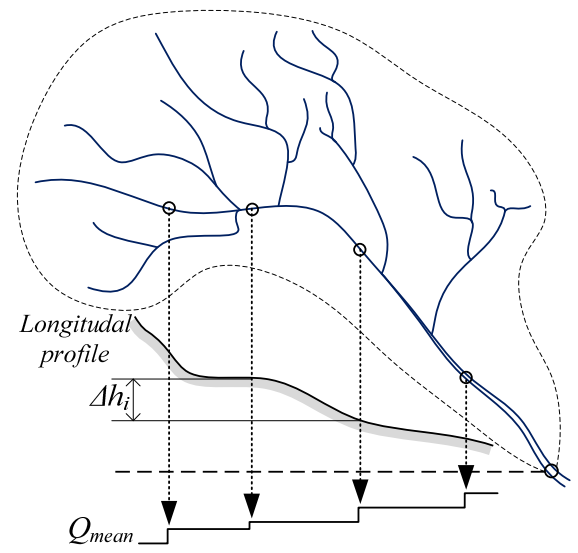

Figure 1 . Line potential $=$ function of mean annual flow and head difference $\Delta h_{i}$ of a reach

Hence a river line potential is observed. The line potential denotes the theoretical potential of streams and rivers which could be harnessed through a continuous chain of imaginary run-of-river plants (a scheme operating with no appreciable water storage). The relevant hydro potential is obtained by subdividing a stream or river into reaches along which discharge and longitudinal slope are approximately uniform as illustrated in Figure 1. It is normally defined on the basis of mean annual discharge and the difference in elevation between beginning and end of each reach. In this study tributary line potential is not considered. More details on how to evaluate river energy potential in (Weiss \& Faeh, 1990; Korkmaz, 2007). When river line potential is established utilizable potential of each river reach is calculated. The utilizable potential is a function of utilizable volume of water and performance curves.

Scope of this work is limited to a basic understanding of modeling hydropower systems from financial point of view with easy to implement linear programming model, check (IRENA, 2012) for more on financial aspect of hydropower systems. This work will give interesting insight for those considering investing in small distributed hydro production. For those interested in technical aspect of small scale HPP check all volumes of (USACE, 1979). Also short insight how to evaluate potential location for HPP is given in (WVU, 1978) and more detailed insight in (ESHA, 2004). A review of different types of models developed to evaluate the cost of the small hydropower projects is given in (Mishra et al., 2011). In (Kucukali, 2011) new risk metric is implemented in hydro model for assessment of investment in river-type hydropower plant projects. To create dynamic models which seek to answer when to invest in small scale hydropower plants consult (Knutsen et al., 2010). Reconnaissance level of detail is warranted and some basic requirements when considering investing in hydropower plants will be discussed.

In Section III problem description and mathematical formulation of a model will be given, in Section IV case study is given of a potential investment in cascaded run-of-the-river HPPs on the Sava river and results are shortly discussed, annual energy production of cascade is estimated and if estimate appear to have a value exceeding the cost of building cascade then a feasibility level of study will be warranted which can be refined and prepared in greater detail that consider construction and maintenance (WVU, 1978).

\section{Problem Description and Formulation}

\subsection{Flow-Duration Curve}

Utilizable volume $V$ of water is defined by flow duration curve (FDC) as illustrated on Figure 2 and pondage dimensions as illustrated on Figure 3. FDCs of observed river reaches are based on daily data since FDC developed from monthly data generally become increasingly less reliable if power storage is relatively small or nonexistent and will overestimate average energy production by as much as 15 to 50 percent, depending on the day-to-day variability of flow (USACE, 1979). 


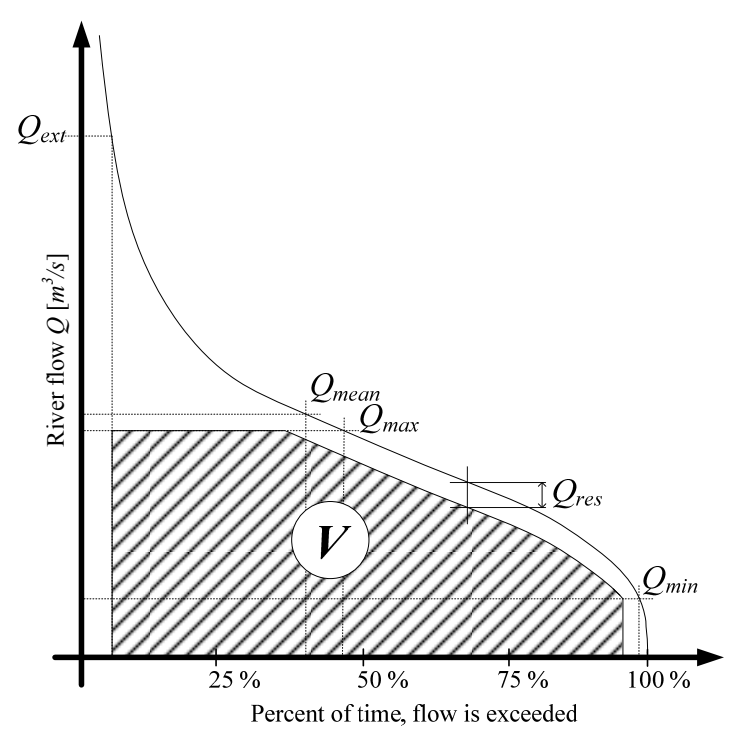

Figure 2. FDC of a river reach

For extremely high flows $Q_{e x t}$ the tailwater will rise so high that the net power head will become too small for the power plant to function. Unless there is available storage to regulate flows to more favorable discharge rates or a sluice to divert extreme flows from main riverbed then HPP will be inoperable in extremely high flows. Residual flow $Q_{\text {res }}$ and HPP minimum turbine discharge $Q_{\min }$ are taken into account to correctly evaluate utilizable volume.

\subsection{Pondage}

Multipurpose projects usually allocate the total available storage to the various purposes proportional to some cost and benefit relationship or to achieve prescribed objectives. Often these objectives have conflicting demands on storage.

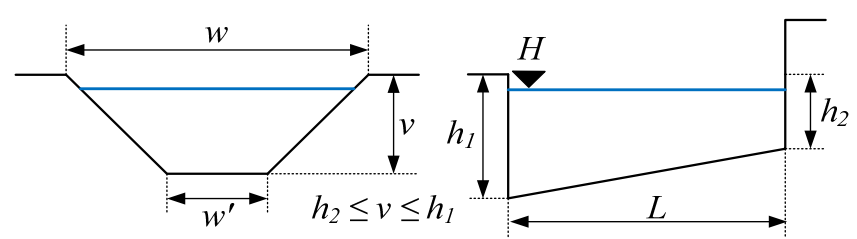

Figure 3. Pondage dimensions

Improved riverbed (Figure 3) of each river reach in this study is considered as pondage of associated HPP. Purpose of run-of-river scheme in this study is to maximize profit form electricity production and to stabilize head $H$ of each river reach and consequently prevent flooding of nearby area. Pondage parameters $w, w^{\prime}, v, L, h_{1}$ and $h_{2}$ are determined by algorithm shown in Figure 8 .

Pondage continuity equation is formulated as (1)-(2). For high exactness $Y$ should strive to 0 .

$$
\begin{gathered}
X(i, t)=X(i, t-1)+\frac{1}{Y} \cdot W(i, t)+\frac{1}{Y} \cdot \sum_{j \in U}[V(j, t)+s(j, t)]-\frac{1}{Y} \cdot[V(i, t)+s(i, t)], \forall i \in I, \forall t \in T \\
X(i, t) \leq X_{\max }(i), \\
X(i, t) \geq X_{\text {min }}(i), \forall i \in I, \forall t \in T
\end{gathered}
$$

The time delay for water transportation is not considered. 


\subsection{Head Dependent Energy Production}

In order to obtain reasonable estimate of the annual power production performance curves are used (Figure 4). Defined performance curves account for efficiency characteristics and operating range limitation consistent with the turbine type likely to be installed (Perez-Diaz et al., 2010). More on performance curves in (Conejo et al., 2002; USACE, 1979).

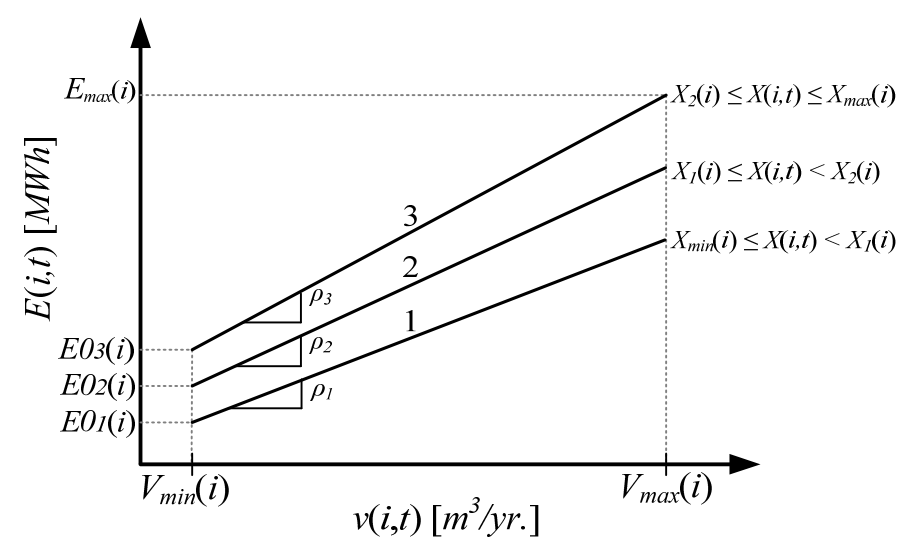

Figure 4. Three-dimensional unit performance curves used for energy evaluation

Generally to assure that best choice of rated head $H_{r}$, rated turbine discharge $Q_{\max }$ and number of units $N$ is selected, all combinations of scenarios $H_{r}, Q_{\max }$ and $N$ should be calculated, procedure for determining optimal rated flow, number of units and head is shown in Figure 8.

General procedure is to calculate and compare energy produced of turbines having a higher and a lower rated flow. Following establishment of the rated flow it needs to be checked if power is being lost because turbine discharge is consistently below lower boundaries, then HPP maximal capacity $P_{\max }$ is lowered and more units are added. If energy production $E(i, t)$ increase is substantial, cost of the alternatives may be determined from the HPP specific investment cost function (Figure 6) and O\&M specific costs function (Figure 7). Also first selection of the number of turbines needs to be compared with the lesser number of units.

The rated head of the turbine can be further refined by optimization in a similar manner. The annual power production is computed for higher and lower heads with the same capacity rating. The rated head yielding the highest annual output should be used.

In this paper performance curves (Figure 4) have been modeled through a piecewise linear formulation of Hill chart (Guan et al., 1999). Figure 4 shows linear performance curves with its associated slope $\rho$ which is defined by HPP conversion capabilities $\left[\mathrm{MW} / \mathrm{m}^{3}\right]$.

There are 3 performance curves associated for 3 water contents (Figure 4).

Activation of corresponding performance curve is done by approach presented in (Conejo et al., 2002), with some improvements presented in (Rajšl \& Ilak, 2012), and is shown in (3)-(9).

$$
\begin{gathered}
X_{\text {avg }}(i, t)=\frac{X(i, t)+X(i, t-1)}{2}, \forall i \in I, \forall t \in T \\
X_{\text {avg }}(i, t) \geq X_{1}(i) \cdot\left[d_{1}(i, t)-d_{2}(i, t)\right]+X_{2}(i) \cdot d_{2}(i, t), \forall i \in I, \forall t \in T \\
X_{\text {avg }}(i, t) \leq X_{\text {max }}(i) \cdot d_{2}(i, t)+X_{1}(i) \cdot\left[1-d_{1}(i, t)\right]+X_{2}(i) \cdot\left[d_{1}(i, t)-d_{2}(i, t)\right], \forall i \in I, \forall t \in T \\
d_{1}(i, t) \geq d_{2}(i, t), \\
d_{2}(i, t) \geq d_{3}(i, t), \\
d_{3}(i, t) \geq d_{4}(i, t), \forall i \in I, \forall t \in T
\end{gathered}
$$


Energy production performance curves (7)-(12).

$$
\begin{gathered}
E(i, t)-E 0_{1}(i) \cdot \text { on }(i, t)-v(i, t) \cdot \rho(i)-E_{\max }(i) \cdot\left[d_{1}(i, t)+d_{2}(i, t)\right] \leq 0 \\
E(i, t)-E 0_{1}(i) \cdot \text { on }(i, t)-v(i, t) \cdot \rho(i)+E_{\max }(i) \cdot\left[d_{1}(i, t)+d_{2}(i, t)\right] \geq 0, \forall i \in I, \forall t \in T \\
E(i, t)-E 0_{2}(i) \cdot \text { on }(i, t)-v(i, t) \cdot \rho(i)-E_{\max }(i) \cdot\left[1-d_{1}(i, t)+d_{2}(i, t)\right] \leq 0 \\
E(i, t)-E 0_{2}(i) \cdot \text { on }(i, t)-v(i, t) \cdot \rho(i)+E_{\max }(i) \cdot\left[1-d_{1}(i, t)+d_{2}(i, t)\right] \geq 0, \forall i \in I, \forall t \in T \\
E(i, t)-E 0_{3}(i) \cdot \text { on }(i, t)-v(i, t) \cdot \rho(i)-E_{\text {max }}(i) \cdot\left[2-d_{1}(i, t)-d_{2}(i, t)\right] \leq 0 \\
E(i, t)-E 0_{3}(i) \cdot \text { on }(i, t)-v(i, t) \cdot \rho(i)+E_{\text {max }}(i) \cdot\left[2-d_{1}(i, t)-d_{2}(i, t)\right] \geq 0, \forall i \in I, \forall t \in T
\end{gathered}
$$

To correctly calculate annual energy production it is necessary to calculate annual utilizable volume $V(i, t)$ correctly (Figure 5). To do that $V(i, t)$ needs to be expressed as a function of HPP water discharge $q(i, t)$ as it is shown in (11).

Turbine water discharge of plant $i$ in time step $t(10)$.

$$
q(i, t)=Q_{\min }(i)+\sum_{b l o k=1}^{2} q_{v}(i, t, b l o k), \forall i \in I, \forall t \in T
$$

Utilizable volume of plant $i$ in time step $t$ (11).

$$
V(i, t)=f(q(i, t))=V_{\text {min }}(i)+v(i, t), \forall i \in I, \forall t \in T
$$

Where $V_{\min }(i)$ is minimum possible utilizable volume of plant $i(12)$ which can be determined from Figure 10 and $v(i, t)$ is variable utilizable volume of plant $i$ in time step $t(13)$.

$$
\begin{gathered}
V_{\min }(i)=g\left(Q_{\min }(i)\right), \quad \forall i \in I, \forall t \in T \\
v(i, t)=H \cdot Y \cdot \sum_{b l o k=1}^{2} \rho_{v}(b l o k) \cdot q_{v}(i, t, b l o k), \forall i \in I, \forall t \in T
\end{gathered}
$$

Function $V(i, t)$ illustrated in Figure 5 is modeled through use of binary variables (14).

$$
\begin{gathered}
q_{v}(i, t, 1) \leq \Delta Q_{1}(i) \cdot \text { on }(i, t) \\
q_{v}(i, t, 1) \geq \Delta Q_{1}(i) \cdot w(i, t, 1) \\
q_{v}(i, t, 2) \leq \Delta Q_{2}(i) \cdot w(i, t, 1) \\
q_{v}(i, t, 2) \geq \Delta Q_{2}(i) \cdot w(i, t, 2), \quad \forall i \in I, \quad \forall t \in T
\end{gathered}
$$

To prevent model to calculate with discharge above turbine maximal discharge $Q_{\max }(i)$ in time period $t$ constraint (15) is defined.

$$
q(i, t) \leq Q_{\max }(i), \quad \forall i \in I, \forall t \in T
$$

Important characteristic of function (11) is its concave nature important for assessment of investment (Figure 5). The greater the chosen value of the maximal turbine discharge, the smaller proportion the year that the system 
will be operating on full power, i.e. it will have a lower capacity factor $n$ as it is depicted on Figure 5 (ESHA, 2004; BHA, 2005).

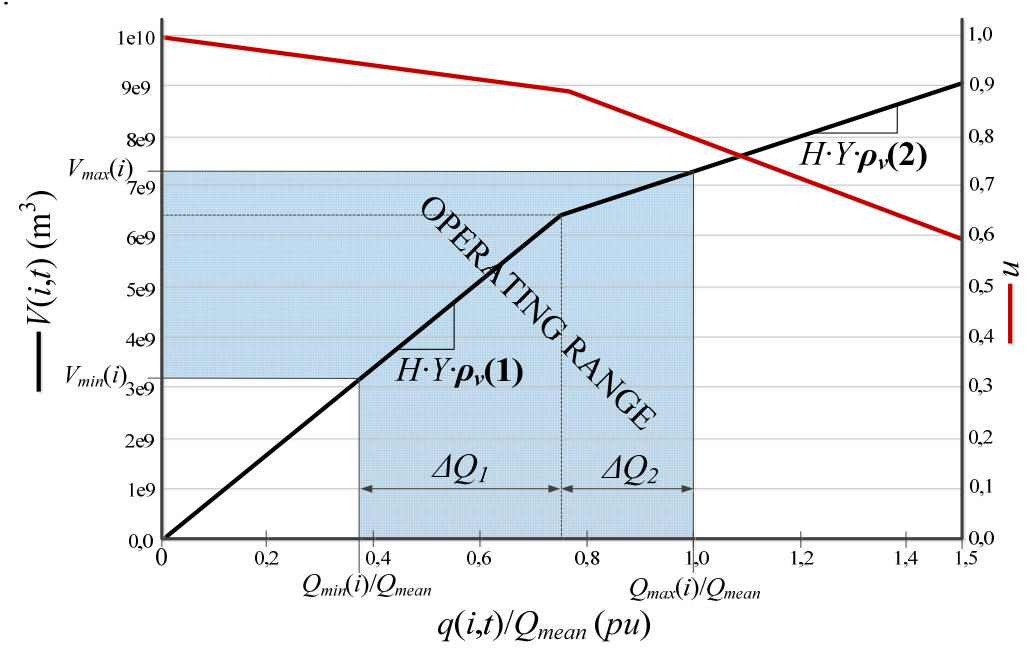

Figure 5. Utilized volume and capacity factor as a function of turbine flow

\subsection{Revenues and Expenses}

The largest share in investment cost for large hydropower plant is typically taken up by civil works for the construction of the hydropower plant (such as dam, tunnels, canal and construction of powerhouse, etc.). Electrical and mechanical equipment usually contributes less to the cost. However, for hydropower projects where the installed capacity is less than $5 \mathrm{MW}$, the costs of electro-mechanical equipment may dominate total cost due to high specific cost of small-scale equipment (IRENA, 2012). Specific cost of investment in HPP is depicted on Figure 6 and is piecewise linear function.

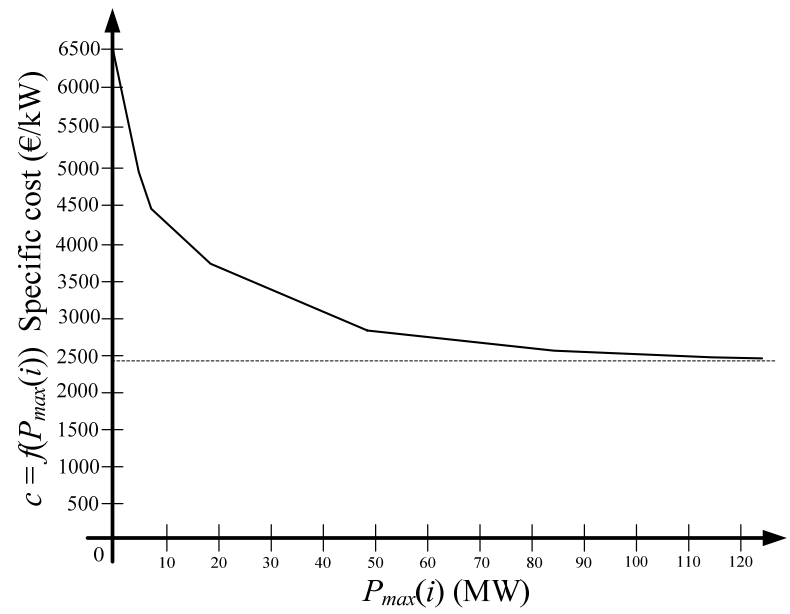

Figure 6. Specific investment cost of a HPP as a function of installed capacity

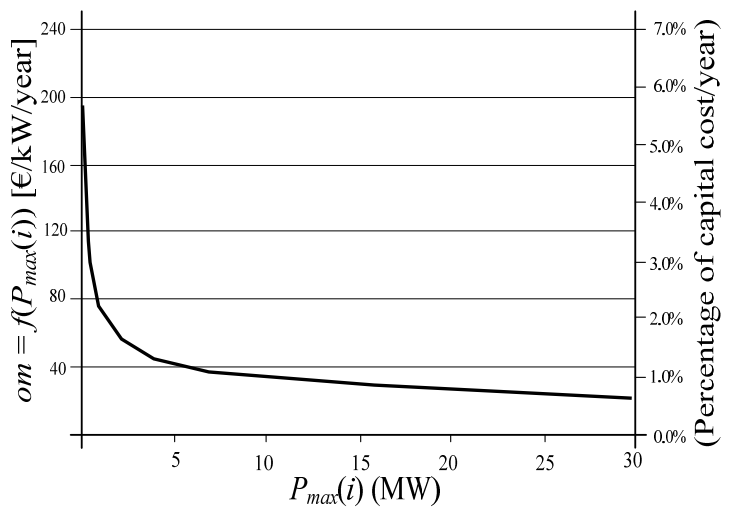

Figure 7. Specific O\&M costs as a function of installed capacity

HPP usually require little maintenance, and operation costs will be low. When in cascade along a river, centralized control can reduce O\&M costs to very low levels. In this study O\&M specific costs are depicted on Figure 7 according to (IRENA, 2012).

\subsection{Objective Function and Algorithm}

Maximize:

$$
N P V=\sum_{t=y+1}^{t=T} \frac{\left(1+i_{x}\right)^{t}(R(t)-O \& M(t))}{(1+r)^{t}}-\sum_{t=1}^{t=y} \frac{\left(1+i_{x}\right)^{t} I(t)}{(1+r)^{t}}
$$


Expression (16) assumes that the project will be developed in $y$ years (time intervals). At the end of $y$-th year the whole development is finished and paid. The electricity revenues and O\&M costs are made effective at the end of each year and begin at the end of the $y$-th year (ESHA. 2004).

Revenue part of (13):

$$
R(t)=\pi_{e}(t) \cdot \sum_{i \in I_{>10 M W}} E(i, t)+\pi_{f i d} \cdot \sum_{i \in I_{\leq 10 M W}} E(i, t) \forall i \in I, \forall t \in T
$$

Operating and maintenance part:

$$
O \& M(t)=\frac{\sum_{i \in I} o m\left(P_{\max }(i)\right)}{100} \cdot \sum_{t=1}^{t=y} \frac{(1+i)^{t} I(t)}{(1+r)^{t}} \forall i \in I, \forall t \in T
$$

Investment cost:

$$
I(t)=\operatorname{weight}(t) \cdot \sum_{i \in I} c\left(P_{\max }(i)\right) \cdot P_{\max }(i) \forall i \in I, \forall t \in T
$$

Expression (20) defines how investment cost is distributed over $y$ years.

$$
\sum_{t=1}^{y} \operatorname{weight}(t)=1
$$

Simple heuristic algorithm for reconnaissance detail of study for cascaded run-of-river HPPs.

\section{Start}

$A \in \mathbb{N}, B \in \mathbb{N}, C \in \mathbb{N}, i \in I$

Matrices $Q_{I \times A}, N_{I \times B}, H_{I \times C}, N P V_{A \times B \times, C}$;

Colum vectors $Q_{\max _{I \times 1}}, N_{I \times 1}, H_{r_{I \times 1}}$;

$a=1,2,3, \ldots, A ; b=1,2,3, \ldots, B ; c=1,2,3, \ldots, C$;

while $a \leq A$

\{

$Q_{\max }=Q_{*, a}$

while $b \leq B$

\{

$N=N_{*, b}$ while $c \leq C$

\{

$$
H_{r}=H_{*, c}
$$

MILP: $\max \{$ Net Present Value $\}$;

$N P V_{a, b, c}=$ Net Present Value;

$$
\begin{aligned}
& c++; \\
& \}
\end{aligned}
$$$$
b++
$$

$a++$;

\}

Matrix maximal value: $\max _{a, b, c}\left\{N P V_{A \times B \times C}\right\}=N P V_{a^{*}, b^{*}, c^{*}}$

Optimal vectors: $Q_{*, a^{*}}, N_{*, b^{*}}, H_{*, c^{*}}$

Figure 8. Heuristic algorithm for assessment of investment in cascaded run-of-river HPPs 
Model is defined as a mixed-integer linear program using indexed assignments (Rosenthal, 2012). The presented results were obtained on $3.4 \mathrm{GHz}$ based processor with 8 GB RAM using CPLEX under General Algebraic Modeling System (GAMS).

\section{Case Study and Results}

Virtual hydropower system (HPS) Sava (Croatia) is modelled as illustrated on Figure 9. Observed 6 river reaches consists of: 6 pondages, 6 run-of-river HPP and a sluice.

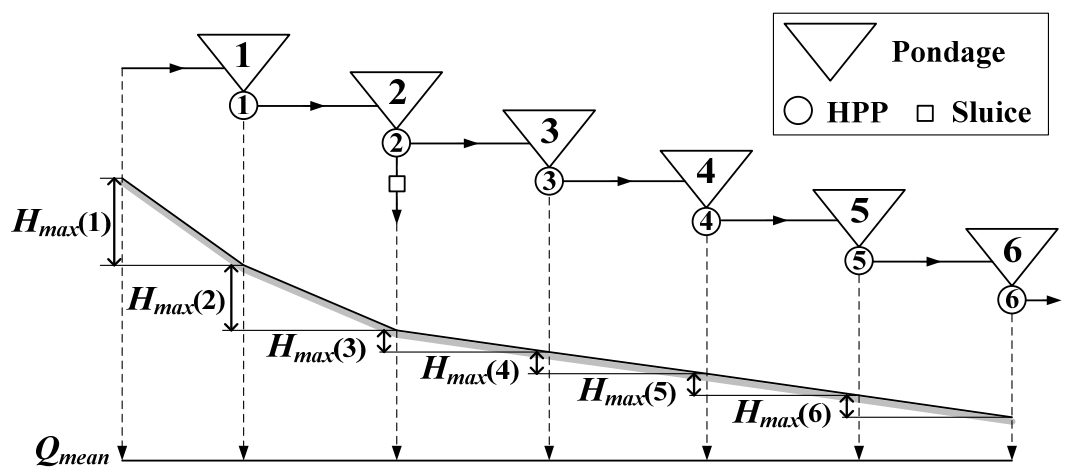

Figure 9. HPS sava

Because of computational effectiveness, it should be noted that time periods of 1 year are considered.

Since there is a sluice in pondage 2 , extreme water flows will not reduce utilizable volume by extreme tailwater rise.

The conventional propeller and very low head (VLH) Kaplan turbines are considered which are operated at power outputs with flows from 40 to 100 percent of rated flow $Q_{\max }(i)$. Performance curves (Figure 4 ) and pondage (Figure 9) parameters are shown in Table 1.

Table 1. HPP performance curves and associated pondage parameters

\begin{tabular}{ccccccccc}
\hline HPP & $\boldsymbol{\rho}_{\mathbf{1}}$ & $\boldsymbol{\rho}_{\boldsymbol{2}}$ & $\boldsymbol{\rho}_{\mathbf{3}}$ & $\boldsymbol{X}_{\boldsymbol{m i n}}$ & $\boldsymbol{X}_{\mathbf{1}}$ & $\boldsymbol{X}_{\mathbf{2}}$ & $\boldsymbol{X}_{\max }$ & $\boldsymbol{H}_{\boldsymbol{m a x}}$ \\
\hline 1 & $2,207 \mathrm{E}-5$ & $2,207 \mathrm{E}-5$ & $2,207 \mathrm{E}-5$ & $3 \mathrm{E} 6$ & $3.3 \mathrm{E} 6$ & $3.66 \mathrm{E} 6$ & $4.078 \mathrm{E} 6$ & 9 \\
2 & $1,839 \mathrm{E}-5$ & $1,839 \mathrm{E}-5$ & $1,839 \mathrm{E}-5$ & $4.6 \mathrm{E} 6$ & $5 \mathrm{E} 6$ & $5.4 \mathrm{E} 6$ & $6.75 \mathrm{E} 6$ & 7,5 \\
3 & $9,197 \mathrm{E}-6$ & $9,197 \mathrm{E}-6$ & $9,197 \mathrm{E}-6$ & $1.2 \mathrm{E} 6$ & $1.4 \mathrm{E} 6$ & $1.7 \mathrm{E} 6$ & $1.903 \mathrm{E} 6$ & 3,75 \\
4 & $9,197 \mathrm{E}-6$ & $9,197 \mathrm{E}-6$ & $9,197 \mathrm{E}-6$ & $1.2 \mathrm{E} 6$ & $1.4 \mathrm{E} 6$ & $1.7 \mathrm{E} 6$ & $1.9406 \mathrm{E} 6$ & 3,75 \\
5 & $9,197 \mathrm{E}-6$ & $9,197 \mathrm{E}-6$ & $9,197 \mathrm{E}-6$ & $0.4 \mathrm{E} 6$ & $0.5 \mathrm{E} 6$ & $0.6 \mathrm{E} 6$ & $0.7875 \mathrm{E} 6$ & 3,75 \\
6 & $9,197 \mathrm{E}-6$ & $9,197 \mathrm{E}-6$ & $9,197 \mathrm{E}-6$ & $1.7 \mathrm{E} 6$ & $2.0 \mathrm{E} 6$ & $2.3 \mathrm{E} 6$ & $2.718 \mathrm{E} 6$ & 3,75 \\
\hline
\end{tabular}

Since there is no important tributary in observed river reaches, one FDC is constructed and is assigned to all 6 river reaches. FDC used in this paper is piecewise linear function with 3 linear parts and is an arithmetic mean of four FDC based on daily flows of periods from time intervals: 1997 to 1987, 1988 to 1993, 1988 to 1998 and 1994 to 1999. Resulting FDC is linearized and is depicted on Figure 10.

Mean annual discharge $Q_{\text {mean }}$ of each river reach is $320 \mathrm{~m}^{3} / \mathrm{s}$. Residual water flow $Q_{\text {res }}$ is $20 \mathrm{~m}^{3} / \mathrm{s}$. Maximal flow $Q_{\text {ext }}$ of each river reach is $800 \mathrm{~m}^{3} / \mathrm{s}$. Electric energy price $\pi_{e}$ is $43.6 € / \mathrm{MWh}$ and is average price of base load power at EPEX Spot (EEX, 2012) for 2003 to 2012 period. Feed-in-tariff $\pi_{f i t}$ is $56 € / \mathrm{MWh}$. Discount rate $r$ is $8.2 \%$. Inflation index $i$ is $2 \%$, number of investment years $y$ is 1 and utilizable volume function slopes $\rho_{v}(1)$ and $\rho_{v}(2)$ are 0.8616 and 0.3618 respectively. Number of units is set to $N(i)=1$ for all $i$ and since stabilizing head $H(i, t)$ of each river reach is one of the major concerns in this study and maximal possible head $H_{\max }(i)$ is predetermined by geographical and urbanization constraints thus rated head $H_{r}(i)$ won't be optimized. 


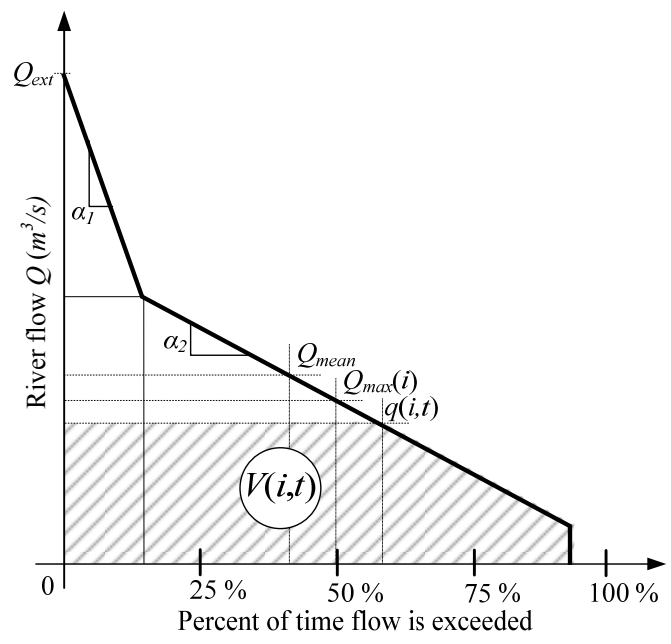

Figure 10. Linearized FDC less residual flow and extreme flows

Consequently results are obtained for set of three observed periods $\boldsymbol{T}_{\max } \in\{\mathbf{2 0}, \mathbf{2 5}, \mathbf{3 0}\}$ with scenario matrix $Q_{I \times A}=[1.5,1.25,1.0,0.75,0.5,0.4,0.33]^{T}[p u]$ with $\boldsymbol{A}=1$, since one scenario of rated flows is used.

Table 2. Output data for time horizon of 20 years

\begin{tabular}{cccccccc}
\hline$Q_{\max } / Q_{\text {mean }}$ & 1,5 & 1,25 & 1 & 0,75 & 0,5 & 0,4 & 0,33 \\
\hline$n$ & 0,61171 & 0,69375 & 0,7787 & 0,8616 & 0,9025 & 0,9259 & 0,9875 \\
\hline$N P V[$ mil. $€]$ & -164 & -120 & $-43,6$ & $-29,3$ & $-37,6$ & $-27,9$ & $-33,5$ \\
$N P V[\%]$ & $-32,929$ & $-27,396$ & $-12,035$ & $-10,135$ & $-16,686$ & $-14,686$ & $-19,606$ \\
$I R R[\%]$ & 3,128 & 4,12 & 6,4842 & 6,731 & 5,64011 & 5,99 & 5,09 \\
$W[\mathrm{GWh}]$ & 646,78 & 638,38 & 565,78 & 461,22 & 314,92 & 253,55 & 215,36 \\
$O \& M[$ mil. $€]$ & 39,5 & 34,6 & 30,9 & 30,1 & 27,2 & 23,8 & 26,2 \\
$I[$ mil. $€]$ & 459 & 402 & 331 & 259 & 198 & 166 & 145 \\
$P_{\max }(1)[\mathrm{MW}]$ & 35,785 & 29,799 & 23,839 & 17,879 & 11,919 & 9,536 & 7,867 \\
$P_{\max }(2)[\mathrm{MW}]$ & 29,798 & 24,832 & 19,866 & 14,899 & 9,933 & 7,946 & 6,556 \\
$P_{\max }(3)[\mathrm{MW}]$ & 14,899 & 12,416 & 9,933 & 7,45 & 4,966 & 3,973 & 3,278 \\
$P_{\max }(4)[\mathrm{MW}]$ & 14,899 & 12,416 & 9,933 & 7,45 & 4,966 & 3,973 & 3,278 \\
$P_{\max }(5)[\mathrm{MW}]$ & 14,899 & 12,416 & 9,933 & 7,45 & 4,966 & 3,973 & 3,278 \\
$P_{\max }(6)[\mathrm{MW}]$ & 14,899 & 12,416 & 9,933 & 7,45 & 4,966 & 3,973 & 3,278 \\
\hline
\end{tabular}

Table 3. Output data for time horizon of 25 years

\begin{tabular}{cccccccc}
\hline$Q_{\max } / Q_{\text {mean }}$ & 1,5 & 1,25 & 1 & 0,75 & 0,5 & 0,4 & 0,33 \\
\hline$n$ & 0,61171 & 0,69375 & 0,7787 & 0,8616 & 0,9025 & 0,9259 & 0,9875 \\
\hline$N P V$ [mil. $€]$ & -130 & -87 & $-11,0$ & $-3,25$ & $-19,4$ & $-12,2$ & $-20,9$ \\
$N P V[\%]$ & $-25,798$ & $-19,889$ & $-3,007$ & $-1,122$ & $-8,498$ & $-6,349$ & $-12,025$ \\
$I R R[\%]$ & 4,8552 & 5,7157 & 7,83875 & 8,06 & 7,12 & 7,39 & 6,593 \\
$W[\mathrm{GWh}]$ & 666,74 & 638,38 & $5,66 \mathrm{E}+07$ & 461,22 & 314,92 & 253,55 & 215,36 \\
$O \& M[\mathrm{mil} . €]$ & 44,0 & 38,6 & 34,5 & 33,6 & 30,3 & 26,5 & 29,2 \\
$I[$ mil. $€]$ & 459 & 402 & 331 & 259 & 198 & 166 & 145 \\
$P_{\max }(1)[\mathrm{MW}]$ & 35,785 & 29,799 & 23,839 & 17,879 & 11,919 & 9,536 & 7,867 \\
$P_{\max }(2)[\mathrm{MW}]$ & 29,798 & 24,832 & 19,866 & 14,899 & 9,933 & 7,946 & 6,556 \\
$P_{\max }(3)[\mathrm{MW}]$ & 14,899 & 12,416 & 9,933 & 7,45 & 4,966 & 3,973 & 3,278 \\
$P_{\max }(4)[\mathrm{MW}]$ & 14,899 & 12,416 & 9,933 & 7,45 & 4,966 & 3,973 & 3,278 \\
$P_{\max }(5)[\mathrm{MW}]$ & 14,899 & 12,416 & 9,933 & 7,45 & 4,966 & 3,973 & 3,278 \\
$P_{\max }(6)[\mathrm{MW}]$ & 14,899 & 12,416 & 9,933 & 7,45 & 4,966 & 3,973 & 3,278 \\
\hline
\end{tabular}


Table 4. Output data for time horizon of 30 years

\begin{tabular}{cccccccc}
\hline$Q_{\max } / Q_{\text {mean }}$ & 1,5 & 1,25 & 1 & 0,75 & 0,5 & 0,4 & 0,33 \\
\hline$n$ & 0,61171 & 0,69375 & 0,7787 & 0,8616 & 0,9025 & 0,9259 & 0,9875 \\
\hline$N P V$ [mil. $€]$ & -104 & $-63,8$ & 14,2 & 16,1 & $-5,87$ & $-56,8$ & $-11,5$ \\
$N P V[\%]$ & $-20,553$ & $-14,387$ & 3,603 & 5,452 & $-2,544$ & $-0,292$ & $-6,547$ \\
$I R R[\%]$ & 5,868 & 6,6225 & 8,58 & 8,7891 & 7,91 & 8,165 & 7,425 \\
$W[\mathrm{GWh}]$ & 679,33 & 638,38 & 565,78 & 461,22 & 314,92 & 253,55 & 215,36 \\
$O \& M[\mathrm{mil} . €]$ & 47,4 & 41,5 & 37,1 & 36,1 & 32,6 & 28,5 & 31,4 \\
$I[\mathrm{mil} . €]$ & 459 & 402 & 330 & 259 & 198 & 166 & 145 \\
$P_{\max }(1)[\mathrm{MW}]$ & 35,785 & 29,799 & 23,839 & 17,879 & 11,919 & 9,536 & 7,867 \\
$P_{\max }(2)[\mathrm{MW}]$ & 29,798 & 24,832 & 19,866 & 14,899 & 9,933 & 7,946 & 6,556 \\
$P_{\max }(3)[\mathrm{MW}]$ & 14,899 & 12,416 & 9,933 & 7,45 & 4,966 & 3,973 & 3,278 \\
$P_{\max }(4)[\mathrm{MW}]$ & 14,899 & 12,416 & 9,933 & 7,45 & 4,966 & 3,973 & 3,278 \\
$P_{\max }(5)[\mathrm{MW}]$ & 14,899 & 12,416 & 9,933 & 7,45 & 4,966 & 3,973 & 3,278 \\
$P_{\max }(6)[\mathrm{MW}]$ & 14,899 & 12,416 & 9,933 & 7,45 & 4,966 & 3,973 & 3,278 \\
\hline
\end{tabular}

\section{Discussion}

Simulation shows that it is unlikely that schemes using significantly more than the mean river flow $\left(Q_{\text {mean }}\right)$ will be economically attractive nor will they be environmentally acceptable (Tables 1-3). Therefore the turbine design flow for a run-of river scheme (a scheme operating with no appreciable water storage) will not normally be greater than $Q_{\text {mean }}$. The exception would be a scheme specifically designed to capture very high winter flows, which is not the case here since pondage parameters are defined by geographical and urbanization constraints (ESHA, 2004; BHA, 2005).

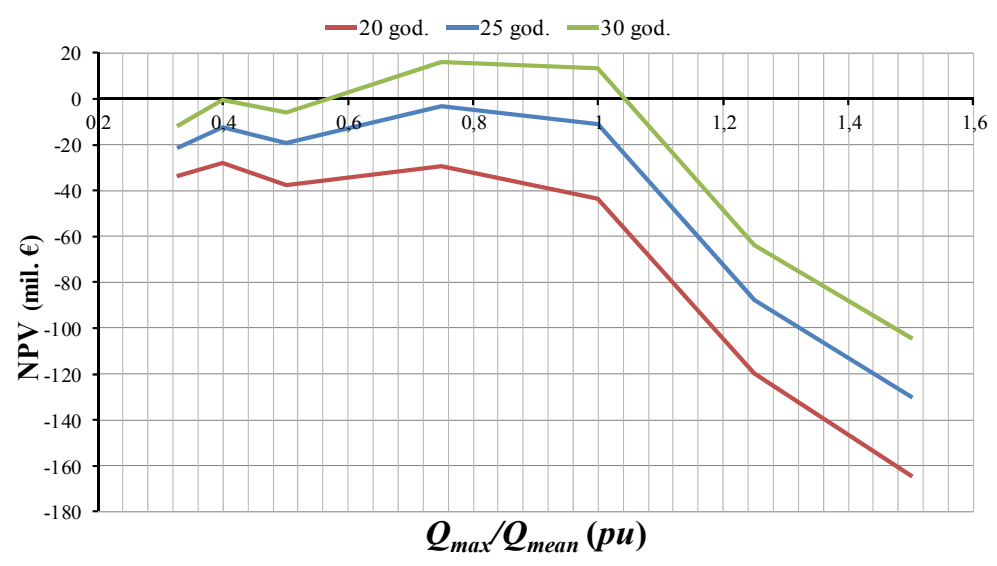

Figure 11. NPV value for different HPP rated flows

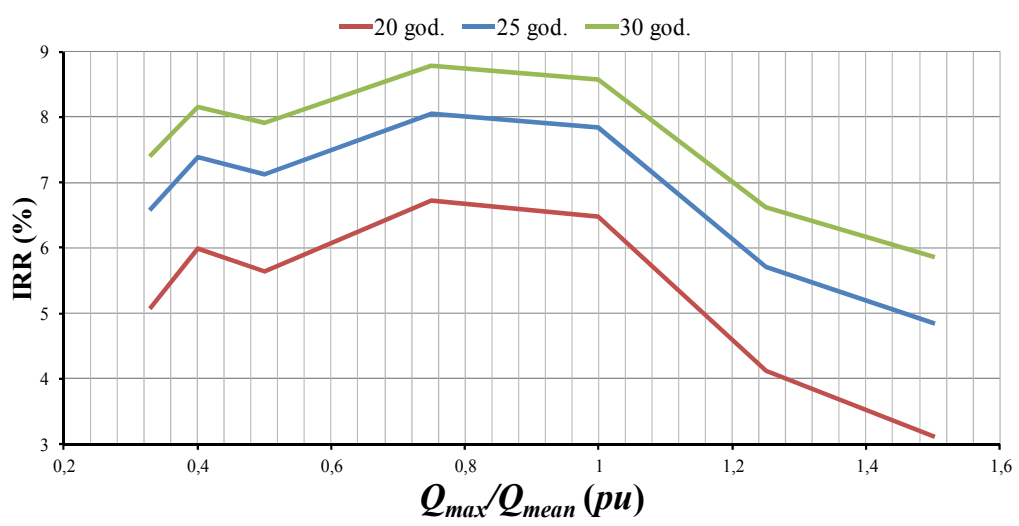

Figure 12. IRR value for different HPP rated flows 
Simulation showed that for observed period of 30 years positive NPV (Figure 11) and highest IRR (Figure 12) were obtained. Model of virtual HPS Sava presented here is flexible and allows simulation for wide range of input data. Project was evaluated to be economically favorable and more detailed energy evaluations needs to be conducted using accurately forecasted data along with different scenarios and shorter time interval which in the case of energy production estimates during feasibility studies should not exceed one month.

Adjusting model to desired accuracy and detail will result in computational intensive simulation and will provide valuable data on run-of-river cascade long-term schedule and its economic justification.

\section{Acknowledgements}

The authors would like to express their sincere thanks to the Department of Energy and Power Systems of University of Zagreb Faculty of Electrical Engineering and Computing.

\section{References}

BHA. (2005). A Guide To UK Mini-Hydro Developments.

Conejo, A., Arroyo, J., Contreras, J., \& Villamor, F. (2002). Self-Scheduling of a Hydro Producer in a Pool-Based Electricty Market. IEEE Transactions On Power Systems, 17(4). http://dx.doi.org/10.1109/TPWRS.2002.804951

EEX. (2012). European Energy Exchange AG. Retrieved January 25, 2012, from http://www.eex.com

ESHA. (2004). Layman's Guidebook on how Develop a Small Hydro Site.

Guan, X., Svoboda, A., \& Li, C. A. (1999). Scheduling hydro power systems with restricted operating zones and discharge ramping constraints. IEEE Trans. Power Syst., 14, 126-131. http://dx.doi.org/10.1109/59.744500

IRENA. (2012). Hydropower Renewable Energy Technologies: Cost Analysis Series, vol. 1.

Knutsen, L. H., \& Holand, R. (2010). Investment Strategy for Small Hydropower Generation Plants in Norway.

Korkamz, O. (2007). A Case Study on Feasibility Assessment of Small Hydropower Scheme.

Kucukali, S. (2011). Risk assessment of river-type hydropower plants using fuzzy logic approach. Energy Policy, 39(10), 6683-6688. http://dx.doi.org/10.1016/j.enpol.2011.06.067

Kucukali, S., \& Baris, K. (2009). Assessment of small hydropower (SHP) development in Turkey: Laws, regulations and EU policy perspective. Energy Policy, 37(10), 3872-3879. http://dx.doi.org/10.1016/j.enpol.2009.06.023

Mishra, S., Singal, S. K., \& Khatod, D. K. (2011). Optimal installation of small hydropower plant. A review, 15(8), 3862-3869. http://dx.doi.org/10.1016/j.rser.2011.07.008

Pérez-Díaz, J. I., Wilhelmi, J. R., \& Arévalo, L. A. (2010). Optimal short-term operation schedule of a hydropower plant in a competitive electricity market. Energy Conversion and Management, 51(12), 2955-2966. http://dx.doi.org/10.1016/j.enconman.2010.06.038

Rajšl, I., Ilak, P., Delimar, M., \& Krajcar, S. (2012). Dispatch Method for Independently Owned Hydropower Plants in the Same River Flow. Energies, 5, 3674-3690. http://dx.doi.org/10.3390/en5093674

Rosenthal, R. (2012). GAMS-A User's Guide; GAMS Development Corporation: Washington, DC, USA, 2012. Retrieved January 25, 2012, from http://www.gams.com/dd/docs/bigdocs/GAMSUsersGuide.pdf

USACE. (1979). U.S. Army corps of enginners. Feasibility Studies for Small Scale Hydropower Additions: Hydrologic Studies Volume III.

Weiss, H. W., \& Faeh, A. O. (1990). Methods for evaluating hydro potential. Proceedings of two Lausanne Symposia.

WVU. (1978). A cross-section, Small Hydroelectric plants. West Virginia University, FS-13.

\section{Copyrights}

Copyright for this article is retained by the author(s), with first publication rights granted to the journal.

This is an open-access article distributed under the terms and conditions of the Creative Commons Attribution license (http://creativecommons.org/licenses/by/3.0/). 